\title{
9 \\ El gobierno de las Sociedades Cooperativas: estudio de la Legislación Cooperativa Vasca
}

\author{
Iñaki del Campo Fernández \\ Universidad de Deusto
}

\begin{abstract}
Sumario: Precedentes legislativos en materia de Sociedades Cooerativas. El Consejo Rector u Organo de Administración.-Directrices de la legislación actual. Referencia a la estructura del órgano de administración.-Formas de estructuración del órgano de administración.-Modificación de la regulación del consejo rector. Ley Vasca de Cooperativas 1/2000.-Estudio de regulación del Organo de Administración. Ley Vasca de Cooperativas. Los Administradores. La Comisión de Vigilancia.-Valoración.-Bibliografía y Conclusiones personales.
\end{abstract}

\section{Precedentes legislativos en materia de Sociedades Cooperativas. El Consejo Rector u Organo de Administración}

Las sociedades cooperativas, como el resto de las demás personas jurídicas, necesitan una organización para desarrollar su actividad, por eso, los instrumentos que componen las sociedades cooperativas, los llamados órganos de ley, son muy importantes para conseguir una buena gestión empresarial y que ofrezca la mayor seguridad jurídica a los terceros.

A causa de las profundas modificaciones que se han ido produciendo en este ámbito concreto de las sociedades cooperativas es conveniente que conozcamos las directrices del régimen orgánico de las cooperativas en la legislación precedente, y en concreto las directrices que rigen en el Organo de Administración o Consejo Rector el cual es objeto de mi estudio, para así, poder entender y valorar el régimen vigente.

\section{Ley de Sociedades Cooperativas de 1931}

En esta ley, la denominación que recibía el actual Consejo Rector era la de Junta Directiva. En esta ley se puede apreciar que la regulación de la junta directiva y de la comisión de inspección de cuentas, cuya constitución sola era exigible en las cooperativas de mas de cien 
socios, era muy deficiente por su parquedad ya que todo el régimen de administración y gobierno de la sociedad cooperativa queda remitido a los estatutos. Además la ley no delimitaba las facultades de la junta directiva, lo que hacía era determinar un sistema de poder residual absoluto a favor de la Asamblea de Socios (actual Asamblea General). Como conclusión de la regulación llevada a cabo por esta ley se puede ver que la junta directiva no podía llevar ordinariamente la sociedad, ya que tenía que estar consultando permanentemente a la asamblea de socios. Esto daba lugar a un cooperativismo asambleario y populista que se consideraba como nada operativo y poco práctico.

\section{Ley de Sociedades Cooperativas de 1942}

La regulación, de la junta rectora y del consejo de vigilancia, que hacía esta ley era más amplia que la realizada por la ley de sociedades cooperativas de 1931, aunque en esta ley se podía observar una falta de claridad y rigor técnico.

En relación con la junta directiva se observaba que ésta actuaba por delegación de la junta general, con lo que en ese momento se ponía en duda que tuviese competencias propias. Además, otro defecto que se podía observar en esta ley es que su regulación se preocupaba mucho por el control gubernativo de las actividades de los órganos de las cooperativas, lo que comprometía gravemente la autonomía de éstas.

\section{El Reglamento de 1971}

Respecto de la junta directiva cabe destacar que el reglamento de 1971 no delimitaba el ámbito de representación del órgano de administración. Sobre esto, la doctrina más autorizada reclamaba a la normativa cooperativa que implantase el sistema propio de los apoderamientos mercantiles, que se concreta en la ilimitabilidad del ámbito de representación del órgano de administración en aquello que sea indispensable para la explotación del objeto social.

Sobre el consejo de vigilancia, también aporta alguna novedad interesante como la fijación del plazo máximo de duración de cuatro años, con posibilidad de reelección.

\section{Ley General de Cooperativas de 1974}

En la Ley de 1974 el órgano de gestión tomó el nombre de Consejo Rector y los encargados de la supervisión de las cuentas anuales 
reciben el nombre de interventores. Este sistema organizativo se corresponde exactamente con el sistema organizativo regulado por la Ley de Sociedades Anónimas: el consejo de administración. En la normativa de los años 1974-1978 se manifestaba el acercamiento del régimen jurídico de las sociedades cooperativas a las sociedades anónimas.

En relación con el consejo rector la normativa cooperativa se basaba en la de las sociedades anónimas al regular el régimen de responsabilidad de los miembros del consejo y la dirección, la acción social e individual de responsabilidad contra los administradores. Hay que decir que esta mejora en la regulación del consejo rector quedó oscurecida al permitir, la Ley de 1974, ampliar los supuestos de competencia exclusiva de la asamblea general a todos los asuntos en que así se acuerde en los estatutos de la sociedad cooperativa. Esto reforzó el papel de la asamblea general (órgano deliberante) en detrimento del consejo rector (órgano representativo y de gestión) lo que pudo dar lugar a un asamblearismo peligroso para el funcionamiento eficaz, e incluso para la propia existencia de la sociedad cooperativa. Para combatir esto era necesario que el consejo rector se conformara como el órgano de gobierno, representación y gestión de la cooperativa con carácter exclusivo y excluyente.

Por otro lado, la regulación de los interventores que realiza esta ley es criticada por haberse inspirado en el régimen de las Sociedades Anónimas, ya que se estableció un sistema interno, dependiente y no profesional, que no dio buenos resultados.

\section{Normativa Cooperativa Post-Constitucional}

En la normativa que floreció después de la Constitución se apreciaba, la influencia del régimen jurídico de la sociedad anónima, pero no se mejoraron las deficiencias que he mencionado anteriormente hasta la creación de la Ley Vasca de Cooperativas de 1993.

\section{Directrices de la legislación actual. Referencia a la estructura del órgano de administración}

La Ley Vasca de Cooperativas de 1993 corrigió las deficiencias que hasta la fecha sopesaban sobre la regulación del consejo rector. Su primera preocupación fue la delimitación de las funciones del ór- 
gano de administración, posteriormente determinó el ámbito de actuación de los administradores, declarando ineficaz frente a terceros toda limitación de sus facultades representativas. Con ello podemos ver que la nueva Ley Vasca de Cooperativas introdujo una regulación especifica sobre el ámbito del poder de representación de los administradores. Además la Ley atribuyó el ejercicio de todas las facultades que no estén expresamente reservadas por la ley o los estatutos a otros órganos sociales y con ello podemos observar que la Ley atribuye al consejo rector un protagonismo dentro de la sociedad cooperativa de primer orden.

De la misma manera introdujo modificaciones en el régimen de control interno y supervisión, al prescindir de los interventores y al introducir la Comisión de Vigilancia, que puede desempeñar un papel importante entre el órgano administrador y las reuniones asamblearias.

\section{Formas de estructuración del órgano de administración}

En el ámbito societario, en general, los sistemas para organizar la administración de la sociedad son dos, el sistema dualista y el sistema monista:

Dualista: En el sistema dualista, de origen germánico, la sociedad tiene un órgano colegiado gestor y de representación denominado dirección o consejo de dirección, y está controlada permanentemente por un órgano de vigilancia denominado consejo de vigilancia.

Hay una parte de la doctrina que aboga a favor del sistema dualista y otra parte de la doctrina que aboga a favor del sistema monista. La doctrina defensora del sistema dualista alega en su favor que la gestión de la empresa tiene que hacerse por dos órganos independientes. Por un lado la gestión y la representación de la sociedad recaen sobre un órgano colegiado altamente cualificado, y por otro lado, el control se confía a un grupo más amplio. Además, una peculiaridad de este sistema es que el control de las cuentas o control contable se confía a expertos profesionales ajenos a la sociedad, que actúan en beneficio de los socios, de los terceros y de la sociedad en general.

Por último hay que responder a la siguiente pregunta ¿Por quién serán elegidos los miembros de la dirección o consejo de dirección en el sistema dualista?

Por la asamblea general. 
Monista: En el sistema monista, latino o francés, a diferencia del sistema dualista, existe un órgano de administración de carácter permanente elegido por la asamblea general. No obstante hay que decir, que en principio, el control de la gestión y de las cuentas lo realizaba un órgano no permanente que emanaba de la mayoría de los socios, los censores o interventores de cuentas, aunque después, al igual que en el sistema dualista, el control contable se confiara a expertos profesionales ajenos a la sociedad.

Actualmente es un hecho típico que en las sociedades con una considerable envergadura, se produzca una diversificación en el seno del órgano de administración entre consejeros ejecutivos o gestores, a los que se encomienda su función a través de la delegación, y consejeros no ejecutivos, a los que corresponde la función de vigilancia, es decir, la supervisión y control de los miembros con facultades gestoras.

La doctrina defensora del sistema unitario ha destacado la flexibilidad de este sistema ya que permite, mediante la delegación, la adaptación del modelo legal básico a la realidad de cada sociedad. Por el contrario los detractores de este sistema, reprochan la falta de transparencia en el ámbito organizativo y se traduce en una confusa delimitación de tareas y responsabilidades que no satisface la gestión de la empresa.

En los estados miembros nos podemos encontrar con tres tipos de situaciones en cuanto a la forma de organizar la administración de las sociedades anónimas, y esto en muchos casos es aplicable a las sociedades cooperativas. Haciendo un barrido podemos comprobar que en algunas legislaciones como la de Inglaterra, Italia y Bélgica se prevé un único órgano de administración para todas las sociedades anónimas. En otras legislaciones se admite la convivencia del sistema dualista y el sistema unitario, pero mientras en algunos estados miembros, como Francia dejan total libertad a las sociedades para elegir la forma de organizar la administración, en otros como Holanda y Dinamarca imponen de forma imperativa para las sociedades que cumplan con determinados requisitos la estructura dualista dejando la libertad de opción para las demás sociedades. La legislación germánica por el contrario es la única que impone la bipartición de los órganos para todas las sociedades anónimas. 
En el ámbito de las sociedades cooperativas, la propuesta de Estatuto de la Sociedad Cooperativa Europea establece lo siguiente «los Estatutos de la Sociedad Cooperativa Europea determinarán la estructura de la sociedad, bien con arreglo a un sistema dualista, o bien con arreglo a un sistema monista». No obstante, hay que decir, que los estados miembros podrán imponer uno u otro sistema a las sociedades cooperativas europeas con domicilio en su territorio. Podemos decir que esta redacción no es acertada porque pone en seria duda la alternativa intermedia, también aplicable a las sociedades cooperativas, que permite la coexistencia de los sistemas dualistas y monista, bien dejando plena libertad a las sociedades para elegir la forma de administración que estimen como apropiada, o bien en la modalidad que impone la forma dualista a las sociedades que cumplen determinados requisitos o la que deja libertad de elección a las demás sociedades que no cumplen con esos requisitos.

La forma de organizar la administración en la Ley Vasca de Cooperativas

La Ley Vasca de Cooperativas (Ley 4/1993 de 24 de junio, modificada por la Ley 1/2000 ) en relación con la forma de organizar la administración recoge el sistema intermedio en la modalidad que obliga a las sociedades cooperativas que cumplen ciertos requisitos, a adoptar la forma dualista y al resto las deja libertad de elección.

¿Cuáles son las cooperativas que por imperativo legal tienen que adoptar el sistema dualista?

Son las sociedades cooperativas con un número de socios igual o superior a cien (100). Éstas tendrán que constituir obligatoriamente una comisión de vigilancia y en los demás casos, será una facultad para las mismas.

Tengo que matizar que el órgano de dirección y el de control operan a un mismo nivel pero está claro que tienen funciones distintas, por lo que la comisión no podrá intervenir directamente en los asuntos de la dirección (gestión y representación) salvo una excepción, podrá representar a la sociedad en caso de impugnaciones judiciales contra la dirección o cualquiera de sus miembros.

Ahora hay que ver si las cooperativas están obligadas a someterse a auditorías externas y en relación con ello vemos que esta obligación se impone cuando así resulte de la Ley de Auditoría de Cuentas y sus normas de desarrollo, cuando así lo solicite una minoría de socios sufi- 
ciente para exigir la convocatoria de la asamblea general y cuando lo prevean los estatutos o lo acuerde la asamblea general o la comisión de vigilancia.

Hay que decir que la Ley Vasca de Cooperativas es la primera norma que introduce en el Derecho interno una de las opciones admitidas en el ámbito comunitario. La justificación de la introducción de esta figura es el refuerzo del órgano de administración. Con esta medida se busca una mayor adaptación a las exigencias de la gestión de la empresa de cierto tamaño, que reclama la separación entre las tareas de gestión y las de control.

Conclusión: La Ley Vasca de Cooperativas ha introducido un régimen interno y de supervisión más adecuado al introducir la Comisión de Vigilancia.

\section{Modificación de la regulación del consejo rector en la Ley Vasca de Cooperativas por la Ley 1/2000}

\section{Reserva de puestos en el Consejo Rector}

(Artículo 41-3 párrafo final)

\section{Artículo 41. Elección de los administradores}

«3. Los administradores serán validamente elegidos por la asamblea general, por el mayor número de votos válidamente emitidos en votación secreta.

Cuando en el consejo rector de la cooperativa se hayan establecido reservas de puestos, salvo disposición contraria de los estatutos, cada colectivo de socios afectado tendrá derecho a elegir directamente en la Asamblea el número de consejeros que le corresponda sin intervenir en la elección de los restantes miembros del Consejo».

La principal innovación respecto a la normativa anterior es que la Ley 4/1993 no posibilitaba la restricción que la nueva ley ofrece a las cooperativas que en los Estatutos Sociales tuviesen reservas de puestos en el Consejo Rector, pues todos los socios podían votar aunque no fuesen socios elegibles.

Con la modificación introducida por la Ley 1/2000 se establece que siempre que no lo prohíban expresamente los Estatutos, solamente los socios colaboradores votarán para elegir a su representante en el Consejo Rector. 
¿Qué conclusión podemos sacar con la modificación de la Ley $1 / 2000$ ?

Que con esta modificación la cooperativa puede restringir el numero de socios electores, es decir, se posibilita el determinar qué socios elegirán a los administradores que tienen reserva de puesto en el consejo rector.

\section{Estudio de la regulación del Organo de Administración en la Ley Vasca de Cooperativas. Modificaciones legislativas que pudiéramos introducir para un buen gobierno en las sociedades cooperativas}

\section{Los administradores}

\section{CONCEPTO Y COMPETENCIAS}

El concepto y las competencias de los administradores están regulados en el artículo $\mathbf{4 0}$ de la Ley Vasca de Cooperativas. La administración es el órgano que tiene competencia exclusiva en la gestión de la sociedad y en la representación de la sociedad en sus relaciones jurídicas con terceros. La Ley delimita claramente el ámbito de competencias de los administradores; además atribuye a los administradores la competencia residual sobre aquellas facultades que no estén expresamente reservadas por ley o por estatutos a otros órganos sociales, aunque no estén vinculadas a las facultades de gestión ni de representación.

La representación que se atribuye a los administradores se extenderá en juicio y fuera de él. Hay que decir que en el ámbito cooperativo se introduce una representación de carácter legal que se extenderá a todos los actos comprendidos en el objeto social sin que las limitaciones estatutarias introducidas en el ámbito de la representación produzcan efectos. Tengo que decir que el ámbito de representación se extiende, además de los actos directamente comprendidos en el objeto social, a los actos conexos que constituyen medios auxiliares para el desarrollo del objeto social. Además, la cooperativa quedará obligada frente a los terceros que obren de buena fe y sin culpa grave, aunque podamos ver que en los estatutos ese acto no esté comprendido en el objeto social; con ello podemos comprobar que la ley extiende al máximo la protección del tercero de buena fe. 
La facultad de representación es una competencia exclusiva de los administradores, aunque esta facultad no tiene que ser necesariamente asumida por todos ellos, por lo que podemos decir que pueden existir administradores que tengan competencia para gestionar la cooperativa y que carezcan de competencia para representar la sociedad. La representación puede atribuirse al consejo rector en su totalidad, a su presidente, a uno o varios consejeros delegados o a una comisión ejecutiva.

\section{LA ELECCIÓN DE LOS ADMINISTRADORES}

La elección de los administradores esta regulado en el artículo $\mathbf{4 1}$ de la Ley Vasca de Cooperativas. Los administradores se configurarán como un órgano colegiado denominado consejo rector, aunque a las cooperativas con un numero de socios igual o inferior a diez, se puede recoger en los estatutos la existencia de un administrador único. El administrador único tendrá que ser necesariamente socio de la cooperativa. En este punto, como modificación legislativa podríamos introducir una pequeña variación, «el administrador único podrá (facultad y no obligación) ser socio en el supuesto que establece la ley y salvo disposición contraria de los estatutos» ya que al igual que en las grandes sociedades cooperativas se permite que una cuarta parte del consejo rector sea formado por profesionales no socios, en el caso del administrador único de una pequeña sociedad cooperativa, se podría permitir, salvo prohibición estatutaria, que en una pequeña cooperativa una persona no socio, desempeñase las labores de gestión y representación. Esta claro que esta persona, no socio, que fuese administrador único de una sociedad cooperativa, solo tendría cabida en el supuesto de que en la pequeña sociedad cooperativa no hubiese ningún administrador y socio que pudiese desempeñar las facultades de gestión y representación en la cooperativa con una eficiencia razonable, para hacer, de esa cooperativa, una sociedad competitiva en el mercado. No es necesario decir que debe ser un profesional de la gestión y de la representación empresarial. Aunque, para respetar la voluntad del legislador, en lugar de proponer la aparición de la figura de administrador único no socio, sugiero que desde la propia cooperativa se fomente la instrucción de los miembros de la cooperativa, para que en un futuro lleguen a ser buenos administradores de la misma, es decir, propongo programas de formación de adultos, en el ámbito de la gestión y de la representación cooperativa. 
Como ya hemos anticipado antes, en las grandes sociedades cooperativas, con la intención de profesionalizar el consejo rector, se permite la posibilidad de que de que una cuarta parte de los miembros del consejo rector pueda ser elegida entre personas no socios, salvo prohibición expresa de los estatutos.

Los administradores serán elegidos por la Asamblea General, por el mayor número de votos válidamente emitidos en votación secreta.

Posteriormente en la Ley Vasca de Cooperativas, se introduce por la Ley 1/2000 la modificación legislativa referente a «las reservas de puestos en el consejo rector», de la cual ya hemos hablado en un apartado anterior.

Además, el nombramiento de administrador puede recaer en una persona jurídica, aunque claro esta, que el ejercicio de las funciones recaerá en una persona física.

El nombramiento de los administradores surtirá efecto desde el momento de su aceptación. La aceptación debe ser presentada a inscripción en el registro de cooperativas dentro de los treinta días siguientes. La inscripción provoca que el nombramiento sea eficaz frente a terceros.

\section{INCAPACIDAD Y PROHIBICIONES}

Las incapacidades y prohibiciones están reguladas en el artículo $\mathbf{4 2}$ de la Ley Vasca de Cooperativas. En la Ley Vasca no se exigen condiciones especiales para ser administrador, solamente se recogen una serie de supuestos en los que no se puede ser administrador, bien por falta de capacidad o bien por incompatibilidad para el cargo. Estos supuestos se regulan en el citado artículo 42 y son los siguientes:

I. Los quebrados y concursados no rehabilitados, los menores de edad e incapacitados, los condenados a penas que conlleven la inhabilitación para el ejercicio de cargos públicos, los que hubieran sido condenados por un incumplimiento grave de leyes o disposiciones sociales y aquellos que por razón de su cargo no puedan ejercer actividades económicas lucrativas.

II. Los funcionarios y personal al servicio de la administración, con funciones a su cargo que se relacionen con las actividades propias de la cooperativa. 
III. Los que desempeñen o ejerzan por cuenta propia o ajena actividades competitivas a las de la cooperativa, o que bajo cualquier forma tengan intereses opuestos a los de la misma.

IV. Los miembros de la comisión de vigilancia y del comité de recursos y los directores-gerentes.

V. Los incursos en los supuestos estatutariamente previstos.

El administrador que este incurso en cualquiera de estas incapacidades o prohibiciones deberá dimitir inmediatamente. En el caso de que no dimitiese podrá ser suspendido temporalmente del cargo por la comisión de vigilancia, y si no lo hiciese lo podrá hacer el consejo rector (hay que decir que este problema continua en el caso de administrador único incapaz o incurso en prohibición, porque la suspensión temporal no es aplicable a este supuesto), hasta la celebración de la asamblea general que es la legalmente competente para cesarlo definitivamente. Hay que hacer una diferenciación:

La asamblea general, cuando se haya producido suspensión cautelar o a petición de cualquier socio, tendrá que destituir al administrador si estima que verdaderamente está incurso en cualquiera de las incapacidades o prohibiciones.

Cuando el administrador esté incurso por la siguiente incompatibilidad «que desempeñe o ejerza por cuenta propia o ajena actividades competitivas a las de la cooperativa, o que bajo cualquier forma tenga intereses opuestos a los de la misma» la asamblea general, si no tiene pruebas irrefutables que le dejen apreciar que el administrador está incurso en una de las causas de incapacidad o prohibición, podrá decidir libremente su cese o continuidad. Toda esta problemática se produce porque este supuesto es de difícil estimación objetiva.

En relación con la cuestión anterior considero que el legislador ha sido muy benévolo al no introducir un limite temporal para destituir a un administrador, que esté incurso en una incapacidad o en una prohibición, eso sí, se deben tener indicios razonables para proceder a la destitución. Por esta misma razón como novedad legislativa, planteo la imposición de una nueva obligación a la asamblea general que se plasmaría en lo siguiente, "La asamblea general tendrá que destituir a los administradores que, de una manera evidente, estén incursos en una incapacidad o prohibición, en el plazo máximo de un mes, prorrogable, por el tiempo que estime necesario, únicamente para los apartados II. y III. del artículo 42 de la Ley Vasca de Cooperativas». 
¿Por que solamente introduzco dos supuestos prorrogables?

Porque estos dos supuestos son causas de difícil estimación objetiva y por ello dejamos un mayor margen, a la asamblea general, para verificar si realmente los administradores están incursos en unas de estas causas y si así lo verifican proceder a la destitución.

\section{REMUNERACIÓN DE LOS ADMINISTRADORES}

La remuneración de los administradores viene regulada en el artículo 43 de la Ley Vasca de Cooperativas. El cargo de administrador de una sociedad cooperativa no tiene por qué ser remunerado, aunque puede ser remunerados si así lo determinan los estatutos, o en su defecto, si así lo dice la asamblea general.

La Ley Vasca no introduce una limitación a la remuneración de los administradores. Como novedad, podríamos introducir en la Ley Vasca un límite estatutario a la retribución de los administradores, cuando ésta consistiese en una participación en las ganancias. El límite podría consistir en atribuir al administrador un porcentaje del beneficio neto en proporción a la aportación realizada por el administrador en las ganancias de la sociedad cooperativa.

Además, el administrador tiene derecho a ser resarcido de los gastos que el cargo le origine. Al administrador se le pagarán los gastos que puedan comprobar, incluso «las dietas». Haciendo referencia a las dietas, habría que realizar una modificación legislativa para limitar los gastos referentes a las dietas de los administradores de la cooperativa.

\section{DURACIÓN Y CESE}

La duración y el cese de los administradores tienen su regulación en el artículo $\mathbf{4 4}$ de la Ley Vasca de Cooperativas. El cargo de administrador es temporal. El plazo de duración de los mandatos es fijado por los estatutos entre dos a cinco años. Aunque la Ley Vasca no lo recoge, debemos decir, que en la inscripción del nombramiento de los administradores practicada en el registro de cooperativas, se indicara el período de duración de los cargos de administradores. Salvo disposición estatutaria en contrario, los administradores podrán ser reelegidos indefinidamente por períodos de tiempo similares. Una vez que los administradores hayan agotado su mandato, éstos continuarán 
provisionalmente en su cargo, hasta que se celebre la próxima asamblea general.

Al respecto del fragmento del precepto que establece que los administradores pueden ser reelegidos indefinidamente, salvo disposición estatutaria en contrario, planteo una invención legislativa que consistiría en lo contrario de lo que establece la Ley Vasca que sería lo siguiente "los administradores podrán ser reelegidos por un máximo de dos mandatos, salvo que en los estatutos se establezca expresamente que los administradores pueden ser reelegidos indefinidamente». Con esta medida pretendo evitar el corporativismo y el acomodamiento de los administradores que gocen con el beneplácito de los miembros de la asamblea general. (*)

La facultad de cesar a los administradores corresponde a la asamblea general, que incluso, puede decidir una destitución sin incluir el asunto en el orden del día, aunque si es así, deberán votar a favor de la destitución dos tercios de los votos presentes y representados en la asamblea. Si algún administrador es destituido, la asamblea en la misma sesión elegirá nuevos administradores, aunque esto tampoco figurase en el orden del día. Aunque la Ley Vasca no lo dice, habrá supuestos en los que ante una destitución de un administrador, habrá que indemnizarle porque así se derive de su contrato.

El cese de los administradores surte efectos desde el momento en que se comunica el cese a los administradores. Por otra parte hay que decir que el cese surte efectos frente a terceros desde que es publicado en el Registro de Cooperativas.

\section{COMPOSICIÓN Y RENOVACIÓN DEL CONSEJO RECTOR}

La composición y renovación del consejo rector se regula en el artículo $\mathbf{4 5}$ de la Ley Vasca. La composición del consejo rector se establecerá en estatutos, la cual no será inferior a tres miembros. Además, en los estatutos también se pueden establecer la existencia de administradores suplentes para los supuestos en que se produzca una baja definitiva de un administrador titular. En el caso de que prevean suplentes, el estatuto fijará su número y determinará el sistema de elección y sustitución. Hay que resaltar que en la actualidad, la Ley Vasca no obliga que los administradores suplentes sean elegidos por la asamblea, por lo que podemos comprobar que en estatutos se puede establecer un sistema libre de elección. 
En mi modesta opinión, creo que al igual que los administradores titulares, los administradores suplentes tienen que ser elegidos por la asamblea general, ya que unos y otros desempeñan las mismas funciones, y por ello creo que la procedencia de la legitimación tiene que ser la misma.

En los estatutos de la cooperativa se podrá prever que en la composición del órgano de gestión y representación, se reflejen entre otras cosas, la distinta implantación geográfica, las distintas actividades desarrolladas por la cooperativa, los diferentes tipos de socios y la proporción entre ellos, y las reservas de puestos. Hay que decir que la ley no establece una lista cerrada de circunstancias que permiten la reserva de puestos sino es una lista abierta que puede ser utilizada como un medio de legitimación legal de casos no expresamente previstos en la norma.

Además, el consejo rector elegirá de entre sus miembros los cargos de presidente y secretario, salvo que los estatutos establezcan que su elección debe realizarse por la asamblea general. De la misma forma, el consejo rector se renovará parcialmente y los consejeros podrán ser reelegidos indefinidamente, salvo previsión estatutaria en contrario. Yo discrepo en esta cuestión, pero sobre ello ya he hablado anteriormente. $\left.{ }^{*}\right)$

\section{FunCIONAMIENTO dEL CONSEJO RECTOR}

El funcionamiento del consejo rector encuentra su regulación en la Ley Vasca y concretamente en el artículo 46. El funcionamiento interno del consejo rector deberá estar regulado en el estatuto social, aunque, hay que decir, que para facilitar y favorecer la operatividad de este órgano en los aspectos no regulados por los estatutos, el propio consejo rector puede regular su funcionamiento.

El consejo será convocado por su presidente y se constituirá de forma correcta cuando concurran a la reunión mas del $50 \%$ de sus componentes. Este quórum es el mínimo legal, aunque hay que decir que los estatutos pueden incrementarlo. La asistencia a las reuniones del consejo rector será necesariamente personal y la ley establece que es imposible que asista un representante a las reuniones del consejo.

En el consejo rector los acuerdos se adoptarán por el voto favorable de más de la mitad de votos de los asistentes, salvo que la ley o 
los estatutos eleven el quórum de la votación (Los acuerdos de gran importancia societaria y económica necesitan $2 / 3$ de votos favorables.)

Por lo demás, cada consejero representa un voto y en el supuesto que se de un empate en la votación de un acuerdo el voto del presidente resolverá el empate.

En último lugar tengo que decir, que la Ley Vasca introduce una novedad respecto de la normativa anterior, ya que prevé la existencia de dos figuras salvo que lo prohíba el estatuto, la comisión ejecutiva y el consejero delegado. Es acertada esta novedad introducida por la nueva Ley Vasca porque estas figuras agilizan notablemente la gestión empresarial. Además, la Ley Vasca establece una serie de supuestos en los que no se permite la delegación. Estos supuestos están regulados en el párrafo $5 .^{\circ}$ del artículo 46.

\section{Responsabilidad de los administradores}

La responsabilidad de los administradores esta regulada en el artículo 47 de la Ley de Cooperativas de Euskadi. La Ley establece que los administradores responderán de manera solidaria por los daños causados por dolo, abuso de poder o culpa o negligencia grave.

¿Qué podemos entender como un administrador diligente para la Ley Vasca?

Que el administrador desempeñe su cargo con la diligencia de un empresario o un representante leal, por lo que responderá por actos negligentes que atenten contra la Ley o contra los estatutos de la sociedad. Incluso, la Ley señala que los administradores deben guardar secreto de las informaciones confidenciales que tengan acerca de la cooperativa, además esta obligación continua aún durante los cuatro años siguientes al cese de su cargo.

Podemos ver que la Ley agrava la responsabilidad de los administradores retribuidos, ya que les hace responder hasta de los actos dañosos cometidos por imprudencia leve.

¿La responsabilidad de los administradores es objetiva (por daño) o subjetiva (por culpa)?

Hay que decir, que el tipo de responsabilidad que recoge la Ley es una responsabilidad objetiva, es decir, el administrador responde por 
el daño que produce el acto a la sociedad y responderá por la cuantía de este. Además, tiene que existir un nexo causal entre la conducta del administrador y el perjuicio causado.

Yo comparto la opinión de otra parte de la doctrina que considera que la responsabilidad es objetiva cuando el acto dañoso del administrador es producido por una conculcación a la Ley o al Estatuto de la sociedad, y por el contrario opera el elemento subjetivo, cuando los administradores hayan producido un hecho dañoso por impericia en el ejercicio de su cargo.

Tengo que destacar que será nula toda cláusula estatutaria que excluya la responsabilidad de los administradores por negligencia.

En cuanto al carácter solidario de la responsabilidad, la Ley establece que cada uno de los administradores responderán por la totalidad de la deuda, salvo aquellos administradores que, demuestren que no han participado en la adopción o ejecución del acto, desconocían su existencia, o que conociéndola, hicieron lo posible para evitar el daño, o al menos que se opusieron expresamente a tal acto o decisión.

Por último, cabe decir que, la Ley Vasca no exonera de responsabilidad a los administradores en el supuesto de que el acto o acuerdo lesivo haya sido adoptado, autorizado o ratificado por la asamblea general. La finalidad que persigue este precepto es la de proteger a los acreedores y a las minorías de la mayoría que escuden los actos de la mayoría, evitar que los administradores no cumplan con su obligación de impugnar los acuerdos que hayan sido adoptados por la asamblea general y no dar pie a que los administradores descarguen su responsabilidad exigiendo a la asamblea, en los supuestos que ésta haya autorizado o ratificado el acto, la exoneración de responsabilidad. Una postura opuesta a la aquí expuesta, es la que adopta la legislación cooperativa alemana que establece que la responsabilidad de los administradores cesa frente a la sociedad si la decisión viene amparada por un acuerdo válido de la asamblea general.

\section{ACCIONES DE RESPONSABILIDAD CONTRA LOS ADMINISTRADORES}

Las acciones de responsabilidad contra los administradores vienen reguladas en el artículo $\mathbf{4 8}$ de la Ley de Cooperativas de Euskadi. En 
primer lugar, hay que decir que la Ley Vasca diferencia dos tipos de acciones para exigir responsabilidad a los administradores:

- La acción social. Con esta acción se pretende el resarcimiento de los daños que ha sufrido la cooperativa por las acciones de sus administradores. En el supuesto de que los administradores fuesen condenados por tal actuación, indemnizará a la sociedad por el importe que sea necesario para reparar el perjuicio patrimonial producido por la sociedad.

La acción será ejercitada por la cooperativa, a través de un acuerdo adoptado por la mayoría de los miembros de la asamblea general, incluso no estando incluido la toma del acuerdo en el orden del día. La asamblea, mediante acuerdo, puede transigir o renunciar al ejercicio de la acción. En relación con esta última cuestión podemos apreciar una laguna legislativa, ya que la Ley Vasca no contempla la posibilidad de que una minoría de socios puedan vetar este acuerdo, por lo que en pro de los intereses de la minoría lo propongo como una alternativa legislativa. Por ultimo, cabe decir, que tanto el acuerdo de promover la acción de responsabilidad, como su transigencia implica la destitución automática de los administradores implicados.

Cuando la cooperativa no ejercite la acción de responsabilidad dentro de un límite temporal de tres meses, a partir de la toma del acuerdo, cualquier socio puede ejercitarla. Si transcurridos seis meses desde que se produjo el daño la acción no hubiese sido ejercitada ni por la asamblea ni por los socios, podrá ser entablada por cualquier acreedor, con la única intención de que se reconstituya el patrimonio de la cooperativa.

La acción prescribe a los dos años de haberse producido el hecho dañoso si éste fuera conocido, o a los dos años desde su conocimiento.

- La acción individual de responsabilidad. Esta acción tiene como peculiaridad que, la difiere de la anterior, que es necesario que el socio o el tercero sea el perjudicado directo por el hecho dañoso, por lo que hacia éstos ira dirigida la indemnización.

IMPUGNACIÓN DE ACUERDOS DE LOS ADMINISTRADORES

La impugnación de a cuerdos de los administradores este regulada en el artículo $\mathbf{4 9}$ de la Ley Vasca. En primer lugar, hay que decir que 
solamente se pueden impugnar los acuerdos tomados por los órganos colegiados del consejo de administración, tanto los de primer orden, como los órganos delegados, es decir, los acuerdos adoptados por el consejo rector o la comisión ejecutiva, que sean contrarios a la Ley (nulos), que vulneren los estatutos (anulables) o que lesionen, en beneficio de uno o varios socios o de terceros, los intereses de la cooperativa (anulables).

¿Quién puede impugnar los acuerdos de los administradores?

Los administradores y la comisión de vigilancia en un plazo de sesenta días desde que se adopto el acuerdo. También podrán impugnar los acuerdos, siempre dentro del limite temporal de sesenta días desde que lo conocieron y nunca rebasando la barrera del año desde que se adopto el acuerdo, los socios que representen un $10 \%$ de los votos sociales.

\section{La Comisión de Vigilancia}

COMPOSICIÓN, MANDATO Y NOMBRAMIENTO

Estas figuras están reguladas en el artículo $\mathbf{5 0}$ de la Ley Vasca de Cooperativas. La comisión de vigilancia es el órgano de fiscalización y control. Por imperativo legal, las cooperativas con un número de socios superior a cien, tienen que constituir obligatoriamente una comisión de vigilancia y será una facultad para las cooperativas con un número de socios inferior a este límite.

Cuando una cooperativa tenga comisión de vigilancia, ya sea por mandato legal o por designación estatutaria, los estatutos fijarán el número de miembros titulares, que no podrá ser inferior a tres, así como los suplentes, y el período de duración del mandato, que no coincidirá con el de los administradores.

Podrán ser miembros de la comisión los socios y si lo permiten los estatutos también podrán formar parte los terceros que reúnan los requisitos de honorabilidad, calificación profesional y experiencia técnica y profesional adecuadas, siempre que el número de estos miembros no exceda del $50 \%$ de los componentes de la comisión.

Los miembros de la comisión serán elegidos y revocados, mediante vocación secreta, por el mayor numero de votos válidamente emiti- 
dos por la asamblea general. Son reelegibles, salvo limitación estatutaria en contrario.

\section{FACULTADES DE INFORMACIÓN}

Esta facultad está regulada en el artículo $\mathbf{5 1}$ de la Ley Vasca. Significa que los administradores, trimestralmente, tienen el deber de informar a los miembros de la comisión, de las actividades y evolución previsible de la cooperativa. Además, los miembros de la comisión tienen la facultad de realizar todas las actuaciones necesarias para el cumplimiento de su función fiscalizadora mediante uno o varios de sus miembros, o bien puede confiar esta tarea a expertos si ninguno de sus miembros lo fuere.

Los miembros de la comisión tendrán acceso a todas las informaciones que le haya comunicado por los administradores. A éstos se les impone la obligación de no poder revelar fuera de los cauces estatutarios, el resultado de las informaciones obtenidas. Hay que decir que ni siquiera podrán revelar estas informaciones a los miembros de la cooperativa.

\section{ÁMBITO DE ACTUACIÓN}

Aspecto regulado en el artículo $\mathbf{5 2}$ de la Ley Vasca. La comisión de vigilancia, en el ejercicio de sus funciones, no podrá convertirse en una traba para la gestión de los administradores, y además no podrá intervenir directamente en la gestión y en la representación de la cooperativa. Hay que matizar que en supuestos extraordinarios la comisión de vigilancia puede ejercer funciones de representación de la sociedad cooperativa.

\section{COMPETENCIAS Y FUNCIONAMIENTO}

Las competencias y el funcionamiento de la comisión de vigilancia están regulados en el artículo $\mathbf{5 3}$ de la Ley Vasca de Cooperativas. La Ley establece una lista cerrada de las competencias que puede desempeñar la comisión de vigilancia en defensa de los intereses de la cooperativa o en defensa de los intereses de los socios; la Comisión de Vigilancia tendrá competencias para fiscalizar las cuentas de la cooperativa, comprobar su documentación y velar por el funcionamiento regular de la misma. En relación con el funcionamiento, éste se ajustará al estatuto o al reglamento interno. 
Con relación a la Comisión de Vigilancia las únicas propuestas legislativas que planteo, dado el silencio legal de la actual normativa, y al igual que recoge la Ley de Cooperativas Alemana, son las siguientes:

- Los miembros de la comisión de vigilancia no podrán ser retribuidos con sujeción a los resultados de la empresa ya que sus funciones no son las de realizar una buena gestión, sino que sus funciones son las de realizar un buen control.

- Para garantizar un control eficaz sobre el consejo rector, los miembros de la comisión de vigilancia no pueden delegar sus funciones.

- Los miembros cesantes del consejo rector no podrán ser elegidos para la comisión de vigilancia hasta que no se apruebe su gestión.

Como valoración personal y en pro de un buen gobierno en las sociedades cooperativas, los miembros del consejo rector deben ser los artífices de la gestión eficiente y efectiva de su sociedad cooperativa, siempre bajo el acecho de la comisión de vigilancia.

El órgano de administración debe obtener beneficios para la cooperativa, mediante el ahorro financiero conseguido a través de una gestión saneada. No obstante, tengo que decir, que el interés personal y directo de los miembros del consejo rector contribuye a una buena gestión.

Después de este repaso legislativo, he llegado a la conclusión que la legislación debe garantizar el control total de sus miembros y debiera obligar a que éstos realicen reuniones periódicas para aprobar cualquier gasto o actuación significativa para la sociedad, y que no se limitasen solamente a revisar y ratificar los gastos financieros y los presupuestos anules de las operaciones.

Es más, cabe decir que el buen gobierno de las cooperativas no se puede dejar al azar. Se tiene que realizar programas de formación de adultos. Sería recomendable un método de formación centrado en el alumno, diseñado para recabar las experiencias de los participantes, con una combinación de teoría, debate y práctica.

Para finalizar tengo que decir, que creo que el movimiento cooperativo se tiene que apoyar en ideales de funcionamiento democrático, gestión por parte de sus miembros (cuando así fuera posible), formación y educación para éstos y una economía autosuficiente. 


\section{Bibliografía}

I. Derecho de las cooperativas. Análisis de la Ley 4/ 1993 de 24 de junio de Cooperativas del País Vasco. Segunda Edición - 2001. Enrique GADEA.

II. Evolución de la Legislación Cooperativa en España. Consejo Superior de Cooperativas de Euskadi - 1999. Enrique GADEA.

III. Legislación Cooperativa de la Unión Europea. Textos Legales / Ministerio de Trabajo y Asuntos Sociales - 2002. Montólo HeRnÁndez, José María.

IV. Glosa de la Ley 1/ 2000 de 29 de Junio de Modificación de la Ley de Cooperativas de Euskadi. Consejo Superior de Cooperativas de Euskadi 2002. Joxe María AizegA, Adrián CelayA, Javier SalaberRIA, Javier SAnz. 